\title{
80 anos de formaç̧ão em Serviço Social: uma trajetória de ruptura com o conservadorismo
}

\author{
80 years of educcacion in Social Work: \\ a break trajectory with conservatism
}

\author{
Priscila Fernanda Gonçalves Cardoso \\ Professora adjunta do curso de Serviço Social da Unifesp/BS - Santos/SP - Brasil. \\ prifgcardoso@gmail.com
}

Resumo: O presente artigo visa realizar análise crítica acerca da formação dos assistentes sociais no Brasil em seus oitenta anos de existência, reconstruindo a trajetória dessa formação desde a primeira Escola de Serviço Social, fundada em 1936. Retoma os currículos que deram base a tal formação desde sua gênese, passando por todos os currículos mínimos aprovados nacionalmente, até as atuais diretrizes curriculares, demonstrando a importante inflexão político-pedagógica realizada na ruptura com o conservadorismo.

Palavras-chave: Formação profissional. Serviço Social. Projetos profissionais.

\begin{abstract}
This article aims to carry out critical analysis of the education of social workers in Brazil in his eighty years of existence, reconstructing the history of this formation since the first School of Social Work founded in 1936. It resumes curricula that based such education since its genesis, through all minimum curricula nationally approved until the current curriculum guidelines, demonstrating the political-pedagogical inflection held in break with conservatism.
\end{abstract}

Keywords: Vocational education. Social Work. Professional project. 


\section{Introdução}

Se as coisas são inatingíveis... ora! Não é motivo para não querê-las... Que tristes os caminhos, senão fora A mágica presença das estrelas!

Mário Quintana, "Das utopias"

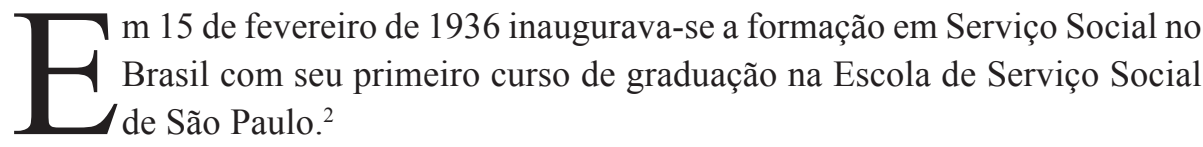

Oitenta anos se passaram, e o projeto de formação profissional dos assistentes sociais ganhou novos sentidos e objetivos, bem antagônicos à sua gênese. Desde a fundação do primeiro curso, diferentes projetos político-pedagógicos construíram a história desta profissão.

Olhar para esses projetos e compreendê-los no processo histórico e social brasileiro é tarefa primordial àqueles que pretendem conhecer esta profissão. Entendemos que a direção social marcada em cada currículo estudado pelos futuros assistentes sociais nesses oitenta anos expressa as diferentes projeções da profissão em disputa pela hegemonia do direcionamento intelectual e político do Serviço Social.

Para efeitos deste artigo, ao nos referirmos à formação profissional, trataremos do processo pelo qual estudantes do curso de Serviço Social passam para se habilitar ao trabalho profissional, portanto, a formação acadêmico-profissional na graduação. Esse, claro, apenas o início de um processo que, no nosso entender, deve ser continuado, visto que tanto nós, como a realidade, vivemos em constante processo de transformação.

Acreditamos que a graduação consiste num marco da formação profissional por ser sua base, na qual o estudante passará por um processo informativo e formativo que orientará sua ação.

Destarte, apontamos a importância desta no que diz respeito não só ao acesso às diferentes informações, até então muitas vezes desconhecidas pelo estudante,

1. Artigo elaborado tendo como base capítulo da tese de doutorado da autora (Cardoso, 2006) orientada pela Profa. Dra. Carmelita Yazbek, a quem agradecemos imensamente pela sempre presente generosidade e compartilhamento do saber.

2. Em 1972 é incorporada a Pontifícia Universidade Católica de São Paulo (PUC-SP). 
mas, em especial, ao processo de formação de um profissional e ao mesmo tempo de um sujeito social que terá na graduação a possibilidade de ver e rever suas posturas na relação com o outro, com o mundo.

Formação que envolve ação/reflexão/ação e perpassa os diferentes níveis de apreensão e dimensões da vida, mexendo com a razão, a emoção, os valores, as crenças, a criatividade, entre outras. Formação que reverbera não só na atuação do profissional, mas na vida social como um todo, mostrando a sua estreita relação entre subjetividade e objetividade, uma vez que terá impactos nesses dois planos e se objetivará na ação profissional e política dos futuros profissionais, nas diferentes dimensões de sua vida, por meio dos distintos papéis que exerce. Formação "[...] e o desenvolvimento de capacidades e habilidades cognitivas e operativas (Libâneo, 1991, p. 100) e, com isso, "estimula-os [os estudantes] a posicionar-se criticamente diante do instituído, transformando-o, se necessário" (Rios, 2001, p. 52).

Em termos do Serviço Social e suas exigências na atualidade, é necessário pensar uma formação que consiga dar respostas às demandas provenientes da "questão social" — objeto de intervenção profissional —, respondendo também às demandas institucionais, sem perder de vista o compromisso com os direitos, a qualidade dos serviços prestados e os sujeitos de nossa ação.

O exercício da profissão exige um sujeito profissional que tenha competência para propor e negociar com a instituição os seus projetos, para defender o seu campo de trabalho, suas qualificações e atribuições profissionais. Requer ir além das rotinas institucionais para buscar apreender, no movimento da realidade e na aproximação as forças vivas de nosso tempo, tendências e possibilidades aí presentes passíveis de serem apropriadas pelo profissional e transformadas em projetos de trabalho profissional. (Iamamoto, 2014, p. 611)

Falamos, portanto, de uma formação que deve dar conta de orientar o pensar e o agir, proporcionando bases reflexivas ao futuro profissional, preparando-o para sua ação como um profissional crítico, reflexivo e interventivo. Um profissional que saiba ler e interpretar a realidade para, a partir de tal leitura, encontrar estratégias e táticas de intervenção nesta, podendo transformá-la ou reforçá-la de acordo com sua visão de homem e mundo, seu projeto profissional e o movimento da própria realidade. 
Em síntese, graduação que seja capaz de formar profissionais competentes. Competência que

não se restringe à dimensão técnico-operativa da prática profissional, mas sim à unidade das dimensões ético-política, teórico-metodológica e técnico-operativa, portanto, não como um ato tecnocrático e burocratizado que determina uma prática neutra e reprodutora das normas institucionais e dos padrões sociais, mas, sim, uma prática crítica e reflexiva que deve ser informada por uma teoria social e por procedimentos metodológicos - em consonância com os valores expressos no código de ética -, que possibilitem ao profissional uma análise do movimento do real e a proposição de estratégias e táticas para o seu enfrentamento sem perder de vista a intencionalidade do seu trabalho e as possibilidades de construções coletivas de táticas e estratégias na relação com os movimentos sociais. (Cardoso, 2013, p. 225)

Compreendendo a unidade entre as dimensões técnico-operativa, ético-política e teórico-metodológica, que dão base à formação em Serviço Social, podemos afirmar que o conteúdo presente na graduação dá direcionamento à intervenção do futuro profissional, sendo, portanto, espaço de disputa de projetos profissionais, na definição dos currículos mínimos (e hoje das diretrizes curriculares), da matriz curricular de cada unidade de ensino e da execução de cada disciplina em sala de aula. Assim, podemos afirmar

a existência de um vínculo orgânico entre projeto profissional, projeto de educação e de universidade e projeto societário. Vínculo orgânico que não se estabelece no cotidiano de modo mecânico, mas mediado por um conjunto de questões e interesses que devem sinalizar para a defesa de uma educação que supõe formar pessoas para a vida, para o mundo e não somente para o exercício profissional, e para tanto pressupõe o fomento do pensamento crítico que possibilite uma ação reflexiva e competente. (Sousa, Santos e Cardoso, 2013, p. 50)

Nesses oitenta anos, as perspectivas conservadora/tradicional e emancipatória/ de ruptura expressas em diferentes projetos profissionais ${ }^{3}$ convivem no seio do Serviço Social alternando-se no que diz respeito ao direcionamento ético e intelec-

3. Sobre tais perspectivas e os projetos profissionais na trajetória do Serviço Social brasileiro, ver Netto (1994), Iamamoto (1992), Silva (1995) e Cardoso (2013). 
tual da categoria, o que Gramsci chamará de hegemonia. ${ }^{4}$ Trata-se da disputa de diferentes compreensões quanto à maneira de pensar e atuar sobre a realidade, que se desdobra na supremacia de uma dessas maneiras sobre as outras. Tal hegemonia se expressa e, ao mesmo tempo, constitui-se a partir da formação acadêmico-profissional - espaço de disputa entre tais projetos através dos projetos político-pedagógicos revelados nos currículos mínimos/diretrizes curriculares na trajetória do Serviço Social.

Desde 1953 os conteúdos e disciplinas eram organizados na forma de um currículo mínimo, que deveria ser seguido por todos os cursos em nível nacional, ou seja, todos os cursos do Brasil tinham o mesmo currículo-base em andamento (com acréscimos que entendessem necessários), definido coletivamente pelas entidades da categoria e aprovado pelo Ministério da Educação (MEC). Em 2012, por determinação do MEC, num processo de contrarreforma da educação, os currículos mínimos foram substituídos por diretrizes curriculares, mais flexíveis e sem determinação de disciplina, apenas conteúdos mais gerais. A partir de tais diretrizes, cada unidade de ensino organiza seu projeto político-pedagógico e sua matriz curricular, não havendo uma unidade de currículos nacionalmente.

Embora cada unidade de formação tenha autonomia para a realização de seu projeto pedagógico, podemos afirmar ainda que o debate e a definição de diretrizes curriculares (e anteriormente do currículo mínimo) apontam uma direção intelectual à formação acadêmico-profissional. Assim, ao olharmos os diferentes momentos de definição dos currículos mínimos/diretrizes curriculares, podemos observar o impacto e a influência dos projetos profissionais no processo de formação dos assistentes sociais, deflagrando a direção social impressa à formação, como veremos a seguir a partir da análise desses currículos desde a primeira escola de Serviço Social. ${ }^{5}$

\footnotetext{
4. A esse respeito consultar o conjunto da obra de Gramsci, em especial Cadernos do cárcere, e, ainda, Coutinho (1989).

5. A apresentação dos tópicos a seguir tem como base a tese de doutorado da autora, na qual realizou pesquisa documental buscando todos os currículos mínimos aprovados nacionalmente. Os currículos de 1936 a 1945 dizem respeito ao primeiro curso de Serviço Social existente no período e foram extraídos de artigo de Yazbek (1980). As informações sobre os demais currículos mínimos foram extraídas dos pareceres e resoluções do Conselho Federal de Educação, a partir de pesquisa realizada junto ao setor denominado Consultec, da PUC-SP, em 2006.
} 


\section{I-Cinquenta anos de formação acadêmico-profissional numa perspectiva conservadora}

Conforme referido anteriormente, iniciava-se em 1936 o curso de Serviço Social no Brasil. Um curso só para mulheres, provenientes da burguesia paulistana, que já realizavam um trabalho social via Igreja Católica. Nas palavras de Iamamoto (1992), uma "especialização da ação social da Igreja", diante da necessidade da formação de profissionais capacitados a assumirem os novos postos de trabalho gestados no processo de industrialização e surgimento da "questão social" no Brasil no início do século XX, com a explicitação do conflito entre os interesses do capital e do trabalho.

O Serviço Social brasileiro nascia no âmbito da contradição capital/trabalho, ou melhor, da necessidade de o Estado e a burguesia industrial em criar mecanismos de apaziguamento e atenuação das expressões dessa relação.

Podemos dizer, portanto, que sua institucionalização é uma consequência da legitimação realizada pelas classes dominantes e impulsionada pela Igreja e que sua formação profissional passa a ser responsabilidade desta, o que lhe confere um caráter conservador e humanista. (Cardoso, 2013, p. 114)

A formação dessas profissionais teve como grande referência o pensamento conservador da Igreja Católica, ${ }^{6}$ tendo o neotomismo como fundamento a partir do estudo de encíclicas papais e de reflexões sobre o papel profissional com base em orientações moralizadoras, no sentido de ensinar à população comportamentos e formas de vida mais "adequadas socialmente", como veremos nos currículos a seguir.

Constituía-se uma formação acadêmico-profissional caudatária do pensamento conservador. ${ }^{7}$ Nas palavras de Iamamoto, "o Serviço Social emerge como uma

6. Tal escola origina-se do desenvolvimento do Centro de Estudos e Ação Social (Ceas) vinculado à Igreja Católica, fundado em 1932.

7. Constitui-se como pensamento a partir do século XVIII em contraposição às revoluções que marcam este século: a Francesa e a Industrial. Seu grande expoente é o inglês Edmund Burke, que tem como uma de suas obras de referência o livro intitulado Reflexões sobre a revolução na França, no qual realiza uma brutal crítica à democracia e apologia à manutenção da ordem, da família, da Igreja e da propriedade privada. "Esse pensamento opõe-se completamente à instauração da razão moderna, do individualismo, da construção do Estado, do coletivismo e da ultrapassagem do sistema feudal para o industrial. Tal contraposição conserva- 
atividade com bases mais doutrinárias que cientificas, no bojo de um movimento de cunho reformista-conservador" (1992, p. 21).

Para Yazbek a primeira fase da formação acadêmico-profissional no Brasil será compreendida entre os anos 1936 a 1945 e caracterizada pela "influência europeia idealista e confessional" (1980. p. 16).

Vejamos, pois, os currículos da Escola de Serviço Social de São Paulo nessa fase:

\begin{tabular}{|c|c|c|}
\hline $\begin{array}{l}\text { 1936: Sociologia Psicologia } \\
\text { Higiene } \\
\text { Anatomia } \\
\text { Estatística } \\
\text { Serviço Social } \\
\text { Enfermagem } \\
\text { Higiene Industrial }\end{array}$ & $\begin{array}{l}\text { 1937: Sociologia } \\
\text { Higiene } \\
\text { Psicologia } \\
\text { Anatomia } \\
\text { Direito } \\
\text { Serviço Social } \\
\text { Técnica } \\
\text { Enfermagem } \\
\text { Moral } \\
\text { Estatística } \\
\text { Direito do Trabalho } \\
\text { Psicotécnica }\end{array}$ & $\begin{array}{l}\text { 1938: Economia } \\
\text { Sociologia } \\
\text { Higiene do Trabalho } \\
\text { Psicologia } \\
\text { Anatomia } \\
\text { Direito } \\
\text { Serviço Social } \\
\text { Enfermagem } \\
\text { Moral } \\
\text { Estatística } \\
\text { Direito do Trabalho } \\
\text { Direito do Menor } \\
\text { Higiene }\end{array}$ \\
\hline $\begin{array}{l}\text { 1939: Economia } \\
\text { Sociologia } \\
\text { Higiene } \\
\text { Psicologia } \\
\text { Anatomia } \\
\text { Direito } \\
\text { Serviço Social } \\
\text { Técnica } \\
\text { Enfermagem } \\
\text { Português } \\
\text { Lógica } \\
\text { Moral } \\
\text { Estatística } \\
\text { Psicologia dos Anormais } \\
\text { Higiene do Trabalho } \\
\text { Puericultura } \\
\text { Direito do Menor } \\
\text { Psicotécnica }\end{array}$ & $\begin{array}{l}\text { 1940: Economia } \\
\text { Sociologia } \\
\text { Higiene } \\
\text { Psicologia } \\
\text { Direito } \\
\text { Serviço Social } \\
\text { Moral } \\
\text { Religião } \\
\text { Estatística } \\
\text { Higiene do Trabalho } \\
\text { Puericultura } \\
\text { Direito do Menor } \\
\text { Psicotécnica } \\
\text { Direito do Trabalho } \\
\text { Psiquiatria } \\
\text { Orientação } \\
\text { Ética Profissional } \\
\text { Pedagogia }\end{array}$ & $\begin{array}{l}\text { 1941: Economia } \\
\text { Sociologia } \\
\text { Higiene } \\
\text { Psicologia } \\
\text { Direito } \\
\text { Serviço Social } \\
\text { Moral } \\
\text { Religião } \\
\text { Estatística } \\
\text { Puericultura } \\
\text { Direito do Menor } \\
\text { Psicotécnica } \\
\text { Psiquiatria } \\
\text { Ética Profissional } \\
\text { Pedagogia } \\
\text { Curso Familiar } \\
\text { Anatomia } \\
\text { Enfermagem } \\
\text { Orientação Profissional }\end{array}$ \\
\hline
\end{tabular}

dora coloca-se como defesa do instituído, em especial no que se refere à propriedade privada e às corporações ditas naturais: a família e a Igreja. O pensamento conservador propõe a retomada do passado como orientadora do presente, o qual perde seu valor perante o passado, pois esse seria a fonte de todo o conhecimento. Conhecimento que provém apenas da experiência, da tradição, da vivência e do sentimento [...]. No conservadorismo valoriza-se a autoridade, a hierarquia, a ordem, a repressão e a disciplina, negando '[...] a razão, a democracia, a liberdade com igualdade, a indústria, a tecnologia, o divórcio, a emancipação da mulher, enfim, todas as conquistas da época moderna' (Barroco, 2008, p. 172)” (Cardoso, 2013, p. 107-108). 


\begin{tabular}{|c|c|c|}
\hline $\begin{array}{l}\text { 1942: Economia } \\
\text { Sociologia } \\
\text { Higiene } \\
\text { Psicologia } \\
\text { Direito } \\
\text { Serviço Social } \\
\text { Moral } \\
\text { Estatística } \\
\text { Higiene do Trabalho } \\
\text { Puericultura } \\
\text { Direito do Menor } \\
\text { Psicotécnica } \\
\text { Psiquiatria } \\
\text { Orientação Profissional } \\
\text { Ética Profissional } \\
\text { Pedagogia } \\
\text { História do Serviço Social } \\
\text { Direito Administrativo } \\
\text { Obstetrícia } \\
\text { Anatomia } \\
\text { Psicologia do Adolescente }\end{array}$ & $\begin{array}{l}\text { 1943: Economia } \\
\text { Sociologia } \\
\text { Higiene } \\
\text { Psicologia } \\
\text { Direito } \\
\text { Serviço Social } \\
\text { Moral } \\
\text { Estatística } \\
\text { Puericultura } \\
\text { Direito do Menor } \\
\text { Psiquiatria } \\
\text { Orientação Profissional } \\
\text { Ética Profissional } \\
\text { Pedagogia } \\
\text { Psicologia do Adolescente } \\
\text { Religião } \\
\text { Higiene Pré-natal } \\
\text { Serviço Social de Menores } \\
\text { Correspondência } \\
\text { Direito do Trabalho } \\
\text { Contabilidade }\end{array}$ & $\begin{array}{l}\text { 1944: Sociologia } \\
\text { Higiene } \\
\text { Psicologia } \\
\text { Direito } \\
\text { Serviço Social } \\
\text { Moral } \\
\text { Estatística } \\
\text { Puericultura } \\
\text { Direito do Menor } \\
\text { Psiquiatria } \\
\text { Ética Profissional } \\
\text { Pedagogia } \\
\text { Religião } \\
\text { Higiene Pré-natal } \\
\text { Serviço Social de Menores } \\
\text { Direito do Trabalho } \\
\text { Economia Política } \\
\text { Psicotécnica }\end{array}$ \\
\hline $\begin{array}{l}\text { 1945: Sociologia } \\
\text { Higiene } \\
\text { Psicologia } \\
\text { Direito } \\
\text { Serviço Social } \\
\text { Moral } \\
\text { Estatística } \\
\text { Puericultura } \\
\text { Direito do Menor } \\
\text { Psiquiatria } \\
\text { Ética Profissional } \\
\text { Pedagogia } \\
\text { Religião } \\
\text { Higiene Pré-natal } \\
\text { Serviço Social de Menores } \\
\text { Direito do Trabalho } \\
\text { Psicotécnica } \\
\text { Pesquisa Social } \\
\text { Administração e Problemas } \\
\text { Econômicos } \\
\text { Psicologia do Adolescente } \\
\text { Serviço Social de Grupo } \\
\text { Pedagogia } \\
\text { Organização Social da } \\
\text { Comunidade } \\
\text { Serviço Social da Indústria } \\
\text { Higiene do Trabalho } \\
\text { Contabilidade } \\
\text { Administração }\end{array}$ & & \\
\hline
\end{tabular}

Fonte: organizada pela autora a partir dos anexos de Yazbek (1980). 
Podemos notar que as disciplinas estudadas nos dez primeiros anos do curso, embora se alternando a cada ano, mantêm uma identidade como projeto pedagógico, demarcando a perspectiva do projeto tradicional/conservador da profissão.

Nota-se a compreensão da profissão vinculada a aspectos da natureza e morais, bem como a necessidade de aprender os elementos das ciências biológicas para a intervenção social em coerência com a referência positivista sob a qual a explicação dos problemas sociais era colocada nos ditos desajustes e problemas emocionais e/ou biológicos. Vemos, nessa direção, o ensino de disciplinas como psiquiatria, psicologia, anatomia, higiene, higiene pré-natal, puericultura, obstetrícia, moral, religião, psicologia, entre outras. (Cardoso, 2013, p. 117)

Assim, tínhamos uma formação que buscava dar bases teóricas e doutrinárias para o profissional a fim de capacitá-lo a compreender a realidade social com um olhar voltado para a dita normalidade, as disfunções, perturbações e patologias às quais os indivíduos estavam sujeitos para que o profissional pudesse intervir na cura, ajustamento e adequação destes às normas sociais e aos padrões de normalidade instituídos, corrigindo todos e quaisquer desníveis e disfunções, tendo por base os princípios cristãos na moralização da sociedade.

O modelo franco-belga limitou-se, portanto, a uma formação essencialmente pessoal e moral, sendo, nesse período, o Serviço Social assumido como uma vocação, e a formação moral e doutrinária, enquanto cerne da formação profissional visou, sobretudo, formar o assistente social para enfrentar, com objetividade, a realidade social. (Silva, 1995, p. 40)

Não é por acaso, também, o registro de disciplinas ligadas ao trabalho, ao "menor" e à contabilidade e, em 1945, a inclusão da disciplina de Serviço Social da Indústria. Vale lembrar que a origem do curso está vinculada a uma estratégia da Igreja Católica para estabelecer uma aproximação junto à classe trabalhadora, num processo de recristianização e de atendimento aos interesses da burguesia.

Não é por acaso, também, a aproximação do Serviço Social da classe dominante não apenas via Estado e suas instituições assistenciais, mas também via as próprias instituições organizadas e geridas pela burguesia nacional. Exemplos são o Senai (Serviço Nacional de Aprendizagem Industrial) e o Sesi (Serviço Social da Indústria). 
A partir de meados dos anos 1940 inicia-se um processo de revisão da profissão no que diz respeito ao seu caráter profissional/científico e à busca de tecnicidade, o que, a partir da influência da metodologia norte-americana, ${ }^{8}$ resulta na incorporação do chamado Serviço Social de Casos, ${ }^{9}$ Grupo ${ }^{10}$ e Comunidade. ${ }^{11}$ Assim, a formação acadêmico-profissional "passa da influência do pensamento conservador europeu, franco-belga, nos seus primórdios, para a sociologia conservadora norte-americana, a partir dos anos 40" (Iamamoto, 1992, p. 26).

Podemos notar tal influência no currículo de 1945, com as disciplinas de Serviço Social de Grupo e Organização Social da Comunidade. No entanto, entendemos que tal influência ganhará expressividade em nível nacional, demonstrando a hegemonia dessa perspectiva, a partir do currículo mínimo de 1953.

Vale frisar que tal processo no interior do Serviço Social está completamente vinculado a elementos sociais e econômicos da conjuntura mundial e brasileira, que imprime à profissão a necessidade de um novo perfil profissional e, consequentemente, uma nova formação acadêmico-profissional.

A partir de 1945, a hegemonia do pensamento europeu, no Ocidente, é substituída, progressivamente, pela influência norte-americana. Os Estados Unidos passam, após a II Guerra Mundial, a consolidar a sua economia e a expandir sua influência econômica notadamente na América Latina, onde impôs a ideologia do planejamento para

8. Tal metodologia baseia-se nos estudos de Mary Richmond e seus sucessores norte-americanos. É incorporada nesse momento em uma relação estreita com o pensamento católico. Para aprofundar tal compreensão, ver Aguiar (2011).

9. "O Serviço Social de Casos é o processo que desenvolve a personalidade através de um ajustamento consciente, indivíduo por indivíduo, entre os homens e seu ambiente" (Richmond, 1972, apud Vieira, 1988, p. 44). Cabe ao trabalho com indivíduos "fornecer serviços básicos práticos e de aconselhamento, de tal modo que seja desenvolvida a capacidade psicológica do cliente e seja levado a utilizar-se dos serviços existentes para atender a seus problemas" (Hamilton, 1958, apud Andrade, 2008, p. 280).

10. "Um método do SS que ajuda os indivíduos a aumentarem o seu funcionamento social, através de objetivas experiências de grupo e a enfrentarem, de modo mais eficaz, os seus problemas pessoais, de grupo ou de comunidade. [...] uma prática que visa minorar o sofrimento e melhorar o funcionamento pessoal e social de seus membros, através de específica e controlada intervenção de grupo, com a ajuda de um profissional" (Konopka, 1979, apud Andrade, 2008, p. 283).

11. "[...] um esforço consciente e deliberado para ajudar as comunidades a reconhecerem suas necessidades e a assumirem responsabilidade na solução de seus problemas pelo fortalecimento de sua capacidade em participar integralmente na vida da nação" (XII Conferência Internacional de Serviço Social, 1962, apud Andrade, 2008, p. 284). 
o desenvolvimento, passando a ter um controle econômico e político, principalmente através dos programas de assistência técnica e ajuda financeira.

Nesse contexto, o Serviço Social brasileiro passa a receber influência do Serviço Social norte-americano, com o retorno das assistentes sociais que foram se especializar naquele país com bolsas de estudo resultantes de convênios [...]. (Silva, 1995, p. 40)

Diante de uma nova conjuntura, nos anos 1960 e 1970, com a ditadura civil-militar no Brasil e a entrada do Serviço Social nas universidades, vive-se mais uma vez um novo processo de revisão na profissão, culminando no que ficou conhecido como movimento de renovação. ${ }^{12}$ Como uma das vertentes/projetos encontra-se a continuidade do projeto tradicional com sua nova roupagem - o projeto modernizador — , que já vinha se gestando desde a década passada, como poderemos notar no currículo de 1953, mantendo a perspectiva conservadora direcionando a formação.

Podemos afirmar, assim, que as mesmas bases filosóficas e doutrinárias perpassam a concepção que orientará tais currículos, porém expressar-se-á a aproximação com o positivismo e a ideologia desenvolvimentista, na busca de uma cientificidade e da preparação técnica para o "fazer profissional". Constitui-se o que Iamamoto denominará como arranjo teórico-doutrinário.

O Serviço Social mantém seu caráter técnico-instrumental voltado para uma ação educativa e organizativa entre proletariado urbano, articulando - na justificativa dessa ação - o discurso humanista, calcado na filosofia aristotélica-tomista, aos princípios da teoria da modernização presente nas Ciências Sociais. Esse arranjo teórico-doutrinário oferece ao profissional um suporte técnico-científico, ao mesmo tempo em que preserva o caráter de uma profissão “especial”, voltada para os elevados ideais de "serviço ao Homem". (1992, p. 21)

12. O chamado "movimento de renovação" foi marcado pelo desenvolvimento de diferentes projetos profissionais (vertente modernizadora, fenomenológica e intenção de ruptura) que, diante das condições objetivas do período, apresentaram distintas formas de compreender e agir na profissão. Definido por Netto (1994, p. 131) como: "O conjunto de características novas que, no marco das constrições da autocracia burguesa, o Serviço Social articulou, à base do rearranjo de suas tradições e da assunção do contributo de tendência do pensamento social contemporâneo, procurando investir-se como instituição de natureza profissional dotada de legitimação prática, através de respostas e demandas sociais e da sua sistematização prática, e de validação teórica, mediante a remissão às teorias e disciplinas sociais". 
Tal perspectiva pode ser notada no primeiro currículo mínimo, promulgado na Lei n. 1.899 , de 13 de junho de $1953,{ }^{13}$ que estabelecia as seguintes disciplinas mínimas:

I - Sociologia e Economia Social;

Direito e Legislação Social;

Higiene e Medicina Social;

Psicologia e Higiene Mental;

Ética Geral e Profissional.

II - Introdução e Fundamentos do Serviço Social;

Métodos do Serviço Social;

Serviço Social de Casos — de Grupo — Organização Social da Comunidade;

Serviço Social em Suas Especializações;

Família - Menores - Trabalho - Médico.

III - Pesquisa Social.

Cremos que, além das disciplinas em si, outra característica marcante dessa lei, demonstrando seu caráter conservador, é uma das condições para a matrícula inicial no curso: "III - Atestado de idoneidade moral".

Do ponto de vista de projeto de formação acadêmico-profissional, esse é o primeiro currículo que marcará a hegemonia do projeto modernizador, não rompendo com a perspectiva conservadora que o antecede e mantendo-se até 1982.

Somente onze anos após a aprovação deste currículo é que se promulga um novo, tendo tido seu parecer em 1962 (n. 286/1962) e resolução em 1964 (n. 512/1964), estabelecendo doze disciplinas básicas como currículo mínimo:

- Introdução ao Serviço Social;

- Serviço Social de Casos;

- Serviço Social de Grupos;

- Desenvolvimento e Organização da Comunidade;

- Administração em Serviço Social;

13. Vale salientar que tal lei, assinada por Café Filho, define não só o currículo mínimo, mas a regularização dos cursos de Serviço Social, das pós-graduações, emissão de certificação, entre outras providências. 
- Psicologia;

- Sociologia;

- Pesquisa Social;

- Economia Social;

- Direito;

- Ética;

- Higiene e Medicina Legal.

Quase dez anos depois, em 1970, esse currículo é revisado, apresentado da seguinte maneira no Parecer n. 242/1970 e Resolução s/n. do Conselho Federal de Educação:

Art. $1^{\circ}-\mathrm{O}$ currículo mínimo do curso de Serviço Social é constituído das seguintes matérias:

a) Ciclo Básico

Sociologia

Psicologia

Economia

Direito e Legislação Social

Teoria do Serviço Social

b) Ciclo Profissional

Serviço Social de Casos

Política Social

Ética Profissional

Serviço Social de Grupo

Serviço Social de Comunidade.

$[\ldots]$

Art. $7^{\circ}$ — À Teoria do Serviço Social cabe dupla função: a de proporcionar, com os elementos recolhidos das diversas ciências sociais do ciclo básico, uma visão integrada com vistas à ação social, e a de ligar a ordem teórica à ordem prática.

Art. $8^{\circ}$ - A Política Social e as disciplinas Serviço Social de Casos, Serviço Social de Grupo e Serviço Social de Comunidade são matérias correlativas e comple- 
mentares que se distinguem pela predominância que têm, na primeira, o conteúdo, as áreas de aplicação e as instâncias da ação social e, nas últimas, os métodos e técnicas correspondentes a essas características básicas.

Podemos perceber que, enquanto projeto pedagógico e vinculação a uma perspectiva ideopolítica, os três currículos (1953, 1964 e 1970) mantêm a mesma direção e não rompem com a perspectiva presente nos primeiros currículos da Escola de São Paulo.

Fica-nos evidente a vinculação dessa proposta curricular ao projeto modernizador, na busca da cientificidade da profissão e do fazer técnico, a preparação profissional para saber trabalhar com indivíduos, grupos e comunidades, como se o que diferenciasse a intervenção profissional do assistente social de outras profissões fossem as técnicas e os instrumentos, e que para cada tipo de abordagem o profissional precisasse saber desenvolver uma metodologia própria de trabalho. A teoria como algo a ser "aplicado" na prática pelo assistente social. A preparação do assistente social focada no fazer, numa prática pragmática que dê resposta às demandas sociais a partir de uma competência operacional, com a supervalorização das técnicas e instrumentos.

A influência americana deu-se mais na construção de uma metodologia "eficaz" no trabalho social. Na construção dessa metodologia, o conteúdo das disciplinas, tanto psicológicas como sociológicas [...] sustenta uma interpretação do desenvolvimento como resultado de capacidades individuais e culturais, pautando-se numa visão harmônica de sociedade e apegando-se ao princípio de neutralidade das ciências.

[...] Metodologicamente, centram-se as relações significativas a nível da comunidade ou de pequenos grupos, desprezando-se o estudo da estrutura global, a partir de uma perspectiva histórica, para concentrar-se no estudo do comportamento dos indivíduos, assumindo o empirismo como tendência dominante, cuja atuação profissional exigia apenas a habilidade para a entrevista, a observação e o questionário.

[...] Ressalta-se que os pressupostos técnicos positivistas se apresentam através dos métodos e não como quadro teórico explícito. (Silva, 1995, p. 41)

Podemos afirmar, após a análise dos dez currículos da primeira Escola de Serviço Social (em São Paulo) e os três currículos mínimos aprovados em nível nacional, que durante quase cinco décadas (1936-1982) a formação acadêmico- 
-profissional esteve vinculada ao pensamento social da Igreja Católica em sua perspectiva conservadora e a busca de consolidação do Serviço Social como profissão, entendendo a necessidade da criação de metodologias próprias de atuação na procura de bases científicas e técnicas para o seu desenvolvimento com suporte da teoria positivista, consolidando um "arranjo teórico-doutrinário".

Tal projeto político-pedagógico marcou fortemente a profissão e o trabalho profissional, construindo uma identidade do Serviço Social atrelada à caridade, ao assistencialismo e ao paternalismo. Marcou também a constituição de um ethos (modo de ser) profissional conservador que compreendia o papel do assistente social na busca da harmonia, do ajuste e da correção dos "desequilíbrios" e "desajustes" dos indivíduos e famílias. Identidade e ethos que mantêm suas raízes até os dias de hoje, tendo, no entanto, perdido sua hegemonia enquanto projeto profissional e sua expressão na formação acadêmico-profissional a partir dos anos 1980, como veremos a seguir.

\section{II - Novo horizonte de formação profissional: a ruptura com o conservadorismo numa perspectiva emancipatória}

Diante da conjuntura dos anos 1980, com o crescimento das lutas sociais e a vinculação de muitos assistentes sociais, estudantes e docentes aos movimentos pela democracia e pelos direitos, bem como com o final da ditadura civil-militar, ocorre no interior do Serviço Social a tomada da direção intelectual e política em busca da ruptura com o conservadorismo. Fruto do movimento de renovação, a "intenção de ruptura" foi caudatária da perspectiva de emancipação, ${ }^{14}$ a partir da

14. "A partir da tradição marxista, emancipação humana é aqui entendida como a possibilidade da inteireza humana, da objetivação de suas potencialidades enquanto gênero humano: a sociabilidade, a universalidade, a consciência e a liberdade. Da 'ultrapassagem da autoalienação'; '[...] aquela que permite a absorção do cidadão abstrato pelo homem individual, que faz deste, em sua vida cotidiana, um ser genérico solidário com os seus semelhantes' (Frederico, 2009, p. 99-106). Para Marx: 'Toda emancipação constitui uma restituição do mundo humano e das relações humanas ao próprio homem’ (Marx, s. d., apud Iasi, 2011. p. 48)" (Cardoso, 2013. p. 56).

A discussão da emancipação humana surge a partir dos escritos do jovem Marx, especificamente em ensaio denominado Sobre a questão judaica, de 1843, no qual o autor trava, pela primeira vez, o debate entre emancipação política e humana (Marx, 1991). 
aproximação do Serviço Social com o marxismo, e ganhou hegemonia no seio da profissão, expressando-se num novo currículo mínimo nessa década.

As entidades da categoria ganham novos direcionamentos e reorganizam seu papel na relação com os assistentes sociais e as instituições. Nesse contexto, a Associação Brasileira de Ensino em Serviço Social (Abess) organiza um processo de revisão curricular amplo, profundo e articulador das diferentes escolas de Serviço Social, que durou anos e culminou em um novo currículo mínimo em $1982,{ }^{15}$ expressando a hegemonia dessa perspectiva em seus conteúdos e a inflexão teórica e política na formação acadêmico-profissional. "O currículo mínimo expressa um processo de transição, parte da resistência acadêmica e política tanto à ditadura militar implantada no país (1964-85) quanto ao Social Work, em sua difundida trilogia, composta por Serviço Social de caso, de grupo e de comunidade" (Iamamoto, 2014, p. 614).

Tal currículo inaugura a expressão, num instrumento legal, da hegemonia dessa perspectiva que se mantém até a atualidade, sendo conhecida como projeto ético-político. As legislações posteriores ${ }^{16}$ incluindo as diretrizes curriculares de 1996, seguirão expressando tal hegemonia.

A partir da aproximação com a tradição marxista ${ }^{17}$ demarca-se a noção de que a intervenção profissional não está solta e dissociada da realidade social; pelo contrário, é só a partir da leitura crítica dessa realidade (como espaço de contradição e conflitos) que o profissional terá condições de desenvolver qualquer metodologia, o que envolve a relação entre refletir/agir/refletir.

Esta concepção é explicitada no Parecer n. 412/1982:

Considera-se que a formação do profissional de Serviço Social tem, como referência básica, o homem como ser histórico de uma realidade em que os relacionamentos emergem, principalmente, da correlação de forças e contradições produzidas pela dinâmica da realidade social. [...] Torna-se, portanto, fundamental capacitar o aluno para compreender e analisar de forma crítica a realidade histórico-estrutural e o contexto institucional, onde se processa a prática do Serviço Social, habilitando-o a

15. Parecer n. 412/82 e Resolução n. 6, de 1982, do Conselho Federal de Educação.

16. Os Códigos de Ética Profissional de 1986 e 1993, bem como a Lei de Regulamentação de 1993.

17. Sobre tal aproximação, sua importância e equívocos, ver Quiroga (1991) e Netto (1994). 
propor e operar alternativas de ação. [...] Trata-se, por conseguinte, de uma formação que se situa no plano da reflexão, tendo em vista o desencadear de um processo de capacitação. Nesta perspectiva, a formação acadêmica pressupõe:

1) Um conhecimento básico enfatizando a ciência do homem e da sociedade.

2) Um conhecimento profissionalizante dos fundamentos teóricos do Serviço Social e suas relações com esses sistemas, assim como uma estratégia de ação que estude a prática das intervenções do Serviço Social com base nas referências teóricas mencionadas.

Vejamos como esta perspectiva se traduziu nas disciplinas e conteúdos, na Resolução n. 6/1982:

Art. $1^{\circ}$ - O currículo mínimo do curso de Serviço Social é constituído das seguintes matérias:

a) Área Básica

Filosofia

Sociologia

Psicologia

Economia

Antropologia

Formação Social, Econômica e Política do Brasil

Direito e Legislação Social

b) Área Profissional

Teoria do Serviço Social

Metodologia do Serviço Social

História do Serviço Social

Desenvolvimento da Comunidade

Política Social

Administração em Serviço Social

Pesquisa em Serviço Social

Ética Profissional em Serviço Social

Planejamento Social 
E nas ementas no Parecer n. 412/1982:

Teoria do Serviço Social:

Ratifica-se a permanência do estudo da Teoria do Serviço Social como conhecimento profissionalizante dos mais fundamentais, devendo ter como enfoques necessários as principais construções teóricas do Serviço Social: objeto, intencionalidade e pressupostos metodológicos de sua práxis; campo de atuação do Serviço Social e sua posição no contexto das Ciências Humanas e Sociais.

\section{Metodologia do Serviço Social:}

Propõe-se a introdução do estudo da Metodologia do Serviço Social (caracterizado no currículo mínimo atual como Serviço Social de Casos, Serviço Social de Grupo e Serviço Social de Comunidade). Este estudo é importante, pois se encarregará das estratégias de ação profissional; visa a capacitação do profissional para operacionalizar os conhecimentos teóricos através de uma ação sistemática pertinente aos vários níveis e áreas de atuação do assistente social.

\section{História do Serviço Social:}

Sugere-se a inclusão do estudo da História do Serviço Social, cuja importância está na análise e compreensão do Serviço Social como fenômeno histórico; a sua institucionalização como resultante de uma demanda social, o seu reconhecimento como resultante das respostas sociais de sua prática, enfim, as relações do processo de institucionalização do Serviço Social como a formação sócio-histórica da sociedade brasileira.

\section{Desenvolvimento de Comunidade:}

Propõe-se a inclusão do estudo de Desenvolvimento de Comunidade, dada a constatação de que o Serviço Social efetivamente atua e sempre atuou como ação catalisadora dos movimentos sociais provocados e espontâneos, carecendo, portanto, de compreender a dinâmica desses movimentos numa perspectiva de estratégia de ação que o capacitem no agir profissional nessa área.

\section{Política Social:}

Ratifica-se a manutenção do estudo da Política Social tendo em vista ser a ação do Serviço Social um dos meios de realização da política social junto aos estratos mais carentes da população, assim como se colocar mesmo como meio estimulador do processo de formulação da política social quando ausente dessas camadas ou de 
sua dinamização quando necessária. Neste sentido, ressaltam-se o estudo e a análise das políticas públicas, suas repercussões sociais e as estratégias de ação do Serviço Social, como executor, estimulador e dinamizador dessa política, assim como da política social em geral.

Administração em Serviço Social:

Baseia-se na proposta de introduzir o estudo da Administração em Serviço Social no currículo mínimo na necessidade de conhecimentos e análise das teorias administrativas e sua relação com as práticas administrativas no Serviço Social (coordenação, assessoria, supervisão e outras) e as vinculações das organizações com o contexto estrutural e conjuntural.

\section{Pesquisa em Serviço Social:}

Sugere-se a inclusão de Pesquisa em Serviço Social, objetivando a capacitação do aluno para uma prática científica, através do estudo dos diferentes métodos e técnicas, suas limitações e alcances, e sua utilização em Serviço Social como um dos instrumentos da relação teoria/prática e com vistas à produção de conhecimentos específicos de Serviço Social.

\section{Planejamento Social:}

Propõe-se a inclusão de Planejamento Social ante a necessidade de habilitação com que, na prática cotidiana, o assistente social está sempre a se defrontar. As exigências se fazem em termos de capacitação para análise e compreensão do planejamento global, suas relações com os planos, programas e projetos sociais; e elementos políticos e técnicos necessários a sua elaboração.

\section{Ética Profissional em Serviço Social:}

Sugere-se a manutenção da Ética Profissional em Serviço Social, visando ao estudo dos componentes axiológicos que integram as construções teórico/metodológicas do Serviço Social por possibilitar a adoção da postura ética do profissional em sua prática social.

O novo currículo apresenta a necessidade do estudo da história da profissão para compreendê-la de maneira contextualizada e circunscrita na realidade social, como uma das práxis sociais, bem como a necessária compreensão das teorias e metodologias que informam sua prática, buscando a noção de totalidade e, ao 
mesmo tempo, ampliando a ideia da intervenção para além do "saber fazer" na afirmação da necessária unidade teórico-prática. Explicita-se ainda o caráter contraditório da prática profissional, ao se situar a profissão como uma "especialização do trabalho na divisão social e técnica do trabalho", bem como a dimensão política a ela inerente.

Embora o currículo de 1982 marque um novo paradigma no que diz respeito à formação acadêmico-profissional, este traz alguns equívocos que provocaram a necessidade de outra revisão, demonstrando o amadurecimento intelectual gestado no interior da profissão, com o aprofundamento da vinculação ao pensamento da tradição marxiana, e a "empreitada" política na defesa dos direitos e da cidadania, que levou a uma atuação profissional cada vez mais voltada para as políticas sociais.

[...] o processo de implantação do currículo de 1982 expressa uma insuficiente apreensão do método crítico-dialético, cujas categorias não são apreendidas como modos de ser na realidade sócio-histórica. (Abess/Cedepss, 1996, p. 148)

Assim, após um vasto processo de discussão envolvendo as entidades da categoria e os profissionais em nível nacional, são aprovadas em 1996 em convenção da Abepss as novas diretrizes curriculares ${ }^{18}$ que apresentam continuidades e rupturas com o currículo anterior.

No Parecer n. 492/2001, os conteúdos curriculares ficam assim definidos:

A organização curricular deve superar as fragmentações do processo de ensino e aprendizagem, abrindo novos caminhos para a construção de conhecimentos como experiência concreta no decorrer da formação profissional. Sustenta-se no tripé dos conhecimentos constituídos pelos núcleos de fundamentação da formação profissional, quais sejam:

- Núcleo de fundamentos teórico-metodológicos da vida social, que compreende um conjunto de fundamentos teórico-metodológicos e ético-políticos para conhecer o ser social.

18. Referimo-nos às diretrizes curriculares como sendo de 1996, entendendo que nossa referência política é o documento aprovado pela Abepss e pela categoria nesse ano, mesmo que a aprovação destas oficialmente tenha se dado (com significativos cortes) apenas em 2002, estando expressas na Resolução CNE/ CES n. 15. Assim, para efeitos desta análise, recorreremos tanto à resolução quanto ao documento da Abepss. 
- Núcleo de fundamentos da formação sócio-histórica da sociedade brasileira, que remete à compreensão das características históricas particulares que presidem a sua formação e desenvolvimento urbano e rural, em suas diversidades regionais e locais.

- Núcleo de fundamentos do trabalho profissional, que compreende os elementos constitutivos do Serviço Social como uma especialização do trabalho: sua trajetória histórica, teórica, metodológica e técnica, os componentes éticos que envolvem o exercício profissional, a pesquisa, o planejamento e a administração em Serviço Social e o estágio supervisionado.

Os núcleos englobam um conjunto de conhecimentos e habilidades que se especifica em atividades acadêmicas, enquanto conhecimentos necessários à formação profissional. Essas atividades, a serem definidas pelos colegiados, se desdobram em disciplinas, seminários temáticos, oficinas/laboratórios, atividades complementares e outros componentes curriculares.

Podemos notar uma diferenciação no que se refere a todos os outros currículos já numa primeira abordagem, no que diz respeito a sua estruturação e concepção. Apresenta-se, aqui, uma noção de totalidade ao pensar a formação de maneira articulada entre núcleos de fundamentação que devem se concretizar não apenas em disciplinas, mas em outros tipos de atividade, ${ }^{19}$ que ampliam a ideia de formação na perspectiva de lidar e estimular as diferentes formas de ensino-aprendizagem e percepção do saber, no reconhecimento das diferentes capacidades e potencialidades do corpo discente e docente.

A ideia de práxis fica, portanto, expressa não como definição das disciplinas ou parte do ementário, mas na lógica da própria formação e estruturação do currículo que deve dar conta de realizar a mediação entre teoria/prática/ética na forma de construir o conhecimento, demonstrando a vinculação à teoria social de Marx, na sua apreensão enquanto método.

A expressão dessa perspectiva política e teórica é anunciada já na apresentação dos núcleos, em que se vê a centralidade no trabalho e o anúncio explícito da compreensão do homem enquanto ser social, entendido o trabalho como fundante desse ser, reafirmando a apropriação da visão ontológica do ser social, presente na teoria marxiana.

19. No documento da Abepss é possível ler a definição de cada uma dessas formas (disciplinas, seminários temáticos, oficinas/laboratórios e atividades complementares). 
A "questão social" passa a ser entendida como o objeto de intervenção da profissão, sendo necessário o desvelamento das antagônicas relações entre capital e trabalho na sociedade de classes para a compreensão das expressões da "questão social" sob as quais a intervenção profissional se realiza. Assim, as diretrizes reafirmam a "questão social" como "base de fundação sócio-histórica da profissão, salientando as respostas do Estado, do empresariado e as ações das classes trabalhadoras no processo de constituição, afirmação e ampliação dos direitos sociais (Abess/Cedepss, 1997a e 1997b)" (Iamamoto, 2014, p. 619).

Pesquisa e ética são entendidas como pressupostos básicos, tendo caráter transversal a todas as disciplinas e conteúdos, diante da concepção da formação de um profissional com postura investigativa e ética consolidadas.

Todos esses aspectos podem ser notados na sugestão que o documento da Abess/Cedepss (1997, p. 70-71) traz acerca das disciplinas: ${ }^{20}$

- Política Social

- Acumulação Capitalista e Desigualdades Sociais

- Fundamentos Históricos e Teórico-metodológicos do Serviço Social

- Processo de Trabalho do Serviço Social

- Administração e Planejamento em Serviço Social

- Pesquisa em Serviço Social

- Ética Profissional

Num avanço em relação ao currículo anterior, e que demonstra também o amadurecimento dentro da tradição marxista, rompe-se aqui a ideia de Teoria/ Método/História como disciplinas separadas. A visão de totalidade e práxis se expressa, também, ao assumir que esse tripé não pode ser separado, pois forma uma unidade na qual a realidade é a base para a compreensão do processo histórico da profissão e da maneira como esta se apropria das diferentes teorias, incorporando-as de acordo com as possibilidades concretas inscritas na própria realidade, bem como construindo respostas a essa realidade a partir da forma como apreendeu tais teorias e elaborou suas metodologias de ação. Assim, as disciplinas de Teoria,

20. Os conteúdos sugeridos para cada disciplina também podem ser vistos no referido documento. Faremos aqui nossa análise levando-os em consideração. 
Método e História são sistematizadas na disciplina de Fundamentos Históricos e Teórico-metodológicos do Serviço Social.

Vemos ainda a sustentação da ação profissional vinculada à defesa dos direitos sociais na garantia da cidadania e da democracia, buscando capacitar o futuro profissional para a elaboração e a execução de políticas sociais, na relação com os diferentes sujeitos sociais presentes na sociedade, numa visão crítica da relação Estado/sociedade civil.

A partir da análise do currículo mínimo de 1982 e das diretrizes curriculares de 1996, podemos notar a inflexão vivida na formação em Serviço Social rumo a uma perspectiva crítica e emancipatória. Percebemos o amadurecimento teórico-político dentro de uma mesma perspectiva e a atualidade do projeto político-pedagógico que direciona a formação dos assistentes sociais nos últimos vinte anos, o que não significa que a realização de avaliações e novas construções não sejam necessárias e que, em coerência com a própria referência de método assumida por essa formação, não sejam fundamentais o encontro de novas estratégias e possíveis revisões diante da realidade atual e do processo de implantação das diretrizes. ${ }^{21}$

\section{Considerações finais}

Oitenta anos desde a primeira aula na Escola de Serviço Social de São Paulo e muitas mudanças! Mudanças na realidade mundial e brasileira, na educação, na universidade. Muitas lutas e muitas conquistas em termos dos movimentos e direitos sociais. Muitas perdas e derrotas nesse mesmo âmbito.

Revendo a trajetória da formação acadêmico-profissional em Serviço Social, a partir da análise de seus currículos mínimos e das diretrizes curriculares, podemos dizer das grandes mudanças e conquistas na perspectiva de garantir a hegemonia de uma proposta certa do profissional e sujeito social que pretende formar: crítico, reflexivo, propositivo, capaz ética, teórica e tecnicamente e, acima de tudo, comprometido com a construção de novas sociabilidades.

21. Acreditamos que a avaliação desse processo nos traga elementos importantes para repensar questões fundamentais como: o estágio, o lugar e a importância da dimensão técnico-operativa, a rediscussão da ética efetivamente como elemento transversal, entre outras. 
Uma trajetória de quase cinquenta anos vinculada a uma perspectiva conservadora e tradicional sobre a realidade e a profissão, direcionando a formação dos assistentes sociais brasileiros e a constituição de uma identidade profissional.

Nessa trajetória, uma importante inflexão na direção da ruptura com essa perspectiva construindo uma nova concepção de profissão e, consequentemente, uma nova identidade profissional. Romper com quase cinquenta anos de conservadorismo na profissão não foi (e não é) tarefa fácil. São trinta e quatro anos de uma revisão curricular que implantou uma perspectiva crítica e emancipatória na formação de assistentes sociais desde 1982, passando por sua reafirmação nas diretrizes de 1996.

Vinte anos decorridos do documento que aprovou as diretrizes curriculares e dos catorze anos de sua oficialização pelo MEC, temos vivido difíceis condições políticas, econômicas e sociais na direção oposta à afirmada nesse projeto de formação: o aprofundamento da política neoliberal, a precarização do trabalho e da educação, o retrocesso de direitos sociais, o alijeiramento da formação, o sucateamento das condições de trabalho nas universidades, os cursos a distância e a radicalização do conservadorismo.

Todas essas questões (e muitas outras) apresentam desafios cotidianos à efetivação desse projeto político-pedagógico em cada unidade de formação acadêmica, bem como desafios profundos a serem enfrentados por nossas entidades da categoria.

Acreditamos que rever essa história seja fundamental para pensarmos os rumos que a formação em Serviço Social necessita tomar, diante das novas requisições e demandas colocadas à profissão, da avaliação do processo de implantação das diretrizes e da realidade política e social no país, sem, no entanto, abrir mão da perspectiva duramente defendida nos últimos trinta anos.

São tempos difíceis, de grandes desafios, mas seguimos tendo as estrelas como norte (como nos inspira Mário Quintana no início deste artigo). Sigamos construindo uma formação capaz de gestar profissionais e sujeitos que se contraponham à barbárie e à desumanização próprias dessa forma social. Sigamos construindo uma formação que possibilite o surgimento de novas sociabilidades. Sigamos acreditando no poético e revolucionário papel da educação!

Recebido em 2/5/2016 - Aprovado em 13/6/2016 


\section{Referências bibliográficas}

ABESS/CEDEPSS. Diretrizes gerais para o Curso de Serviço Social (com base no currículo mínimo aprovado em Assembleia Geral Extraordinária de 8 nov. 1996). Cadernos ABESS, São Paulo, n. 7, 1997.

. Proposta básica para o projeto de formação profissional — documento Abess/Cedepss (nov. 1995). Serviço Social \& Sociedade, São Paulo, n. 50, 1996.

AGUIAR, A. G. Serviço Social e filosofia: das origens a Araxá. 6. ed. São Paulo: Cortez, 2011.

ANDRADE, M. R. A. O metodologismo e o desenvolvimentismo no Serviço Social brasileiro - 1947 a 1961. Serviço Social \& Realidade, Franca, v. 7, n. 1, 2008.

CARDOSO, P. F. G. Havia uma ética no meio do caminho? A afirmação da necessária centralidade da ética na formação dos assistentes sociais. Tese (Doutorado) — Pontifícia Universidade Católica, São Paulo, 2006.

Ética e projetos profissionais: os diferentes caminhos do Serviço Social no Brasil. Campinas: Papel Social, 2013.

CARVALHO, R.; IAMAMOTO, M. V. Relações sociais e Serviço Social no Brasil. 11. ed. São Paulo: Cortez, 1996.

COUTINHO, C. N. Gramsci: um estudo sobre seu pensamento político. Rio de Janeiro: Campus, 1989.

IAMAMOTO, M. V. Renovação e conservadorismo no Serviço Social: ensaios críticos. São Paulo: Cortez, 1992.

IAMAMOTO, M. V. A formação acadêmico-profissional no Serviço Social brasileiro. Serviço Social \& Sociedade, São Paulo, n. 120, 2014.

MARX, K. A questão judaica. São Paulo: Moraes, 1991.

NETTO, J. P. Ditadura e Serviço Social: uma análise do Serviço Social no Brasil pós-64. 2. ed. São Paulo: Cortez, 1994.

QUIROGA, C. Invasão positivista no marxismo: manifestações no ensino da metodologia no Serviço Social. São Paulo, Cortez, 1991.

RIOS, T. A. Compreender e ensinar: por uma docência da melhor qualidade. São Paulo: Cortez, 2001. 
SILVA, M. O. S. (Org.). O Serviço Social e o popular: resgate teórico-metodológico do projeto profissional de ruptura. São Paulo: Cortez, 1995.

SIMIONATTO, I. Gramsci: sua teoria, incidência no Brasil, influência no Serviço Social. São Paulo: Cortez, 1995.

SOUSA, A. A. S.; SANTOS, S. M. M.; CARDOSO, P. Ética e Serviço Social: um itinerante caminhar. Temporalis, Brasília, n. 25, 2013.

VIEIRA, B. O. Serviço Social: processos e técnicas. 6. ed. Rio de Janeiro: Agir, 1988.

YAZBEK, M. C. A escola de Serviço Social no período de 1936 a 1945. Cadernos PUC, São Paulo, n. 6, 1980. 